\title{
Uspješna primjena izvantjelesne membranske oksigenacije za liječenje pacijenata u kardiogenom šoku nakon transplantacije bubrega
}

\section{Successful use of extracorporeal membrane oxygenation in the treatment of a patient with cardiogenic shock after renal transplantation.}

\author{
Zdravko Jurilj*, Berislav Barbalić, Branka Čačić, Hana Tunaj
}

\begin{abstract}
Sažetak. Cilj: Veno-arterijska izvantjelesna membranska oksigenacija (engl. veno-arterial extracorporeal membrane oxygenation; VA-ECMO) metoda je pružanja potpore funkciji srca u pacijenata $s$ kardiogenim šokom kod kojih medikamentozna terapija nije dovoljna. Cilj rada je ukazati, kroz prikaz liječenja pacijenta koji je u ranom poslijeoperacijskom tijeku po transplantaciji bubrega razvio kardiogeni šok, na veliki potencijal primjene izvantjelesne mehaničke potpore radu srca kao metode liječenja kardiogenog šoka u ovih pacijenata, koja je, u opisanom tijeku liječenja, omogućila ne samo preživljavanje pacijenta, već i očuvanje funkcije transplantata. Prikaz slučaja: Na Odjel intenzivnog liječenja (OIL) primljen je šezdesetjednogodišnji pacijent sa završnim stadijem kronične bubrežne bolesti, kojem je učinjena transplantacija bubrega. Tijek operacijskog zahvata komplicirao se razvojem značajne hemodinamske nestabilnosti. Pacijent je, usprkos svim poduzetim medikamentoznim mjerama liječenja, razvio infarkt miokarda $s$ kardiogenim šokom. $S$ obzirom na to da je stanje bilo refraktorno na primijenjenu medikamentoznu terapiju, donesena je odluka o primjeni izvantjelesne mehaničke potpore cirkulaciji. Mehanička potpora dovela je do hemodinamske stabilizacije pacijenta i poslužila je kao most do oporavka srčane funkcije $s$ uspješnim očuvanjem funkcije transplantata. Zaključci: U rastućem broju radova mehanička cirkulatorna potpora je označena kao budućnost liječenja kardiogenog šoka, neovisno o njegovoj etiologiji. Kao i sve druge metode liječenja, nosi rizik od razvoja komplikacija, koji se razvojem tehnologije polako smanjuje. Ona postaje sve dostupnija te se njezina primjena širi na različite skupine pacijenata. Važno je naglasiti da je za uspjeh terapije nužna suradnja specijalista različitih specijalnosti u liječenju ovako kompleksnih pacijenata.
\end{abstract}

Ključne riječi: izvantjelesna mehanička cirkulatorna potpora; kardiogeni šok; transplantacija bubrega; veno-arterijska izvantjelesna membranska oksigenacija
Klinika za anesteziologiju i intenzivno liječenje, Klinički bolnički centar Rijeka, Rijeka, Hrvatska

\author{
*Dopisni autor: \\ Zdravko Jurilj, dr. med. \\ Klinika za anesteziologiju i intenzivno \\ liječenje, Klinički bolnički centar Rijeka, \\ Krešimirova 42, 51000 Rijeka \\ E-mail: zdravko.jurilj@gmail.com
}

http://hrcak.srce.hr/medicina 
condition was refractory to the applied drug therapy, a decision was made to initiate the extracorporeal mechanical support. Mechanical support led to hemodynamic stabilization of the patient and served as a bridge to recovery of cardiac function with successful preservation of transplant function Conclusions: In the growing number of papers that support this, mechanical circulatory support is the future of treatment for cardiogenic shock, regardless of its etiology. It is a method that carries its own risks which are slowly diminishing with the development of technology. It is becoming more widely available and its application is expanding to different patient groups. It is important to emphasize that the success of therapy requires the participation of specialists of different specialties in the treatment of such complex cases.

Key words: cardiogenic shock; extracorproreal mechanical support; kidney transplantation; veno-arterial extracorporeal membrane oxygenation

Kronična bubrežna bolest (KBB) sve je veći javnozdravstveni problem čija učestalost, kako u svijetu, tako i u Hrvatskoj, raste. lako se transplantacija bubrega smatra najboljim oblikom liječenja pacijenata $u$ završnom stadiju KBB-a, ona također nosi sa sobom rizik mnogobrojnih perioperacijskih komplikacija, od kojih neke mogu biti i životno ugrožavajuće.

\section{UVOD}

Kronična bubrežna bolest (KBB) sve je veći javnozdravstveni problem čija učestalost raste. Prema dostupnim podacima, KBB u nekom obliku zahvaća i do $11 \%$ svjetske populacije, osobito među starijima od 65 godina ${ }^{1}$. Pacijenti koji dostignu završni stadij kronične bubrežne bolesti pripremaju se za neki oblik nadomještanja bubrežne funkcije ${ }^{2}$. Transplantacija bubrega predstavlja zlatni standard u liječenju završnog stadija zatajivanja bubrega, ali sa sobom također nosi rizik mnogobrojnih perioperacijskih komplikacija, od kojih neke mogu biti i životno ugrožavajuće. Kardiovaskularna događanja su najčešći uzrok smrtnosti kod ove skupine pacijenata, koja doseže vrhunac upravo u perioperacijskom periodu ${ }^{3}$.

Veno-arterijska izvantjelesna membranska oksigenacija (engl. veno-arterial extracorporeal membrane oxygenation, VA-ECMO) metoda je pružanja potpore funkciji srca tijekom kardiogenog šoka kod kojeg nije došlo do oporavka na primijenjenu medikamentoznu terapiju. Radi se o metodi liječenja koja omogućuje privremenu mehaničku potporu cirkulaciji, ali i nadomješta funkciju pluća u izmjeni plinova. Važno je naglasiti da ovaj oblik liječenja ne liječi osnovni problem u pacijenta, već omogućuje hemodinamsku stabilizaciju uz rasterećenje srčanog mišića do njegova oporavka ili do ugradnje trajne mehaničke potpore, tj. transplantacije.

U ovom članku predstavljamo tijek liječenja šezdesetjednogodišnjeg pacijenta koji je poslije transplantacije bubrega razvio infarkt miokarda $s$ posljedičnim kardiogenim šokom koji je uspješno liječen primjenom izvantjelesne mehaničke cirkulacijske potpore. Cilj članka je pokazati da se ovakve pacijente uspješno može liječiti ovom metodom i da, primijenjena na vrijeme i na pravilan način, omogućuje i očuvanje funkcije transplantata.

\section{PRIKAZ SLUČAJA}

Šezdesetjednogodišnji pacijent primljen je radi transplantacije kadaveričnog bubrega u Klinički bolnički centar (KBC) Rijeka. Po primitku u bolnicu nadležni anesteziolog ga je pregledao u pripremi za predstojeći operacijski zahvat. Pacijent se unatrag nekoliko godina liječio redovitom hemodijalizom zbog kronične bubrežne bolesti 5. stupnja. Također je bolovao od ishemijske bolesti srca, arterijske hipertenzije, periferne arterijske bolesti, šećerne bolesti ovisne o inzulinu te sekundarne anemije. Kod pacijenta je 1985. godine učinjena ljevostrana nefrektomija, a 2015. godine učinjena je kirurška revaskularizacija miokarda. Po pregledu je klasificiran u četvrtu kategoriju pacijenata prema klasifikaciji Američkog društva anesteziologa (engl. American Society of Anesthesiologists (ASA) Physical Status Classification System $)^{4}$. U sklopu pripreme za zahvat zatražen je prijeoperacijski pregled kardiologa s ultrazvukom (UTZ) srca koji je pokazao blago sniženu sistoličku funkciju srca s dijastoličkom disfunkcijom lijevog ventrikula (LV) I/IV stupnja. Od drugih nalaza tijekom pregleda ističemo uvećan lijevi atrij te akineziju apikalne polovice septuma, apikalne trećine inferiorne stijenke i cijelog apeksa srca. Kod pacijenta se također učinila standardna laboratorijska obrada u kojoj, osim kronično povišenih biokemijskih parametara bubrežne funkcije, nije bilo 
osobitosti. Po učinjenim pregledima pristupilo se kirurškom zahvatu.

Zahvat je učinjen u općoj balansiranoj anesteziji. Prije indukcije, s obzirom na povišen perioperacijski rizik, uz standardno praćenje, postavljena je kanila za invazivno mjerenje arterijskog tlaka te je indukcija učinjena uz pažljivo titriranje doza anestetika. Po indukciji kod pacijenta se postavio centralni venski kateter u desnu gornju jugularnu venu. Ubrzo po indukciji i početku zahvata dolazi do hemodinamskog pogoršanja pacijenta bez signifikantnog kirurškog događanja. Započelo se s mjerama hemodinamske stabilizacije pacijenta primjenom bolusa kristaloidnih otopina i vazokonstriktoronom potporom za koju je korišten noradrenalin u dozi od $0.3 \mathrm{mg} / \mathrm{kg} / \mathrm{min}$ kontinuirano putem perfuzijske pumpe (Arterenol, Sanofi Aventis, Paris, Francuska i B Braun Medical INC infuzijska pumpa,Melsungen, Njemačka). Tijekom zahvata pacijent je bio tahikardan s izmjenama sinusnog ritma i fibro-undulacije atrije, zbog čega se uveo antiaritmik amiodaron (Cordarone, Sanofi Aventis, Paris, Francuska i B Braun Medical INC infuzijska pumpa, Melsungen, Njemačka), najprije bolusno u dozi od $150 \mathrm{mg}$, a poslije i kontinuirano u dozi od $900 \mathrm{mg}$ kroz 24 sata. Pacijenta se po svršetku zahvata, zbog i dalje prisutne hemodinamske nestabilnosti, primilo na Odjel intenzivnog liječenja (OIL).

Pacijenta se ubrzo po prijemu u OIL probudilo i ekstubiralo, nakon čega je disao spontano, suficijentno. Tijekom prvih nekoliko sati od povratka iz operacijske sale dolazi do porasta biokemijskih pokazatelja anaerobnog metabolizma, odnosno laktata, unatoč intenzivnoj volumskoj nadoknadi i primijenjenoj medikamentoznoj terapiji. $U$ terapiju se uključila i inodilatacijska potpora inhibitorom fosfodiesteraze enoximonom $3 \mathrm{mg} / \mathrm{kg} / \mathrm{min}$ (Perfan, Carinopharm GmbH, Elze, Njemačka i $B$ Braun Medical INC infuzijska pumpa, Melsungen, Njemačka). U laboratorijskim pretragama se prati pozitivna dinamika troponina T koji unutar nekoliko sati od zahvata raste do $454 \mathrm{ng} / \mathrm{L}$, radi čega se konzultira nadležna kardiološka služba. Po pregledu kardiologa i učinjenom kontrolnom UTZ-u srca, u tom trenutku se ne postavlja indikacija za koronarnu intervenciju, nego nastavak medikamentoznog liječenja. Prvog poslijeoperacijskog dana, usprkos svim do tada poduzetim mjerama intenzivnog liječenja, ne dolazi do poboljšanja hemodinamskog statusa pacijenta, niti poboljšanja laboratorijskih parametara. Pacijent je afebrilan, ali dolazi do porasta leukocita do $37,8 \times 10^{9} \mathrm{i}$ koncentracije C-reaktivnog proteina (CRP) do 223 $\mathrm{mg} / \mathrm{L}$. U tom trenutku i dalje se nastavilo s empirijskom antimikrobnom terapijom ceftriaksonom u dozi od 2 g intravenski (i. v.) jednom dnevno (Lendacin, Sandoz GmbH, Camberley Surrey, Ujedinjeno Kraljevstvo). Pacijenta se zbog pogoršanja respiracijskih parametara ponovno intubiralo te se nastavilo s mehaničkom ventilacijom. U daljnjem tijeku liječenja započelo se s kontinuiranom analgosedacijom primjenom midazolama kontinuirano u dozi od 1,6 mg/kg/min (Midazolam, B Braun, Melsungen, Njemačka i B Braun Medical INC infuzijska pumpa, Melsungen, Njemačka) i sufentanila u dozi od $0.01 \mathrm{mg} / \mathrm{kg} / \mathrm{min}$ (Sufentanyl, Renaudin, Itxassou, Francuska i B Braun Medical INC infuzijska pumpa, Melsungen, Njemačka). Potrebno je naglasiti da je pacijent ubrzo po povratku iz sale imao spontanu diurezu, ali kako bi se održala diureza $>1 \mathrm{ml} / \mathrm{kg} / \mathrm{h}$, u terapiju je uveden kontinuirano furosemid (Furosemid, Belupo, Koprivnica, Hrvatska) u dozi od 7,8 mg/kg/ min. Zbog obilne volumske nadoknade koja se primijenila u svrhu stabilizacije pacijenta i posljedičnog volumskog opterećenja, u konzultaciji $s$ nefrologom započeto je dijalitičko liječenje - kontinuirana venovenska hemodijafiltracija (engl. Con-

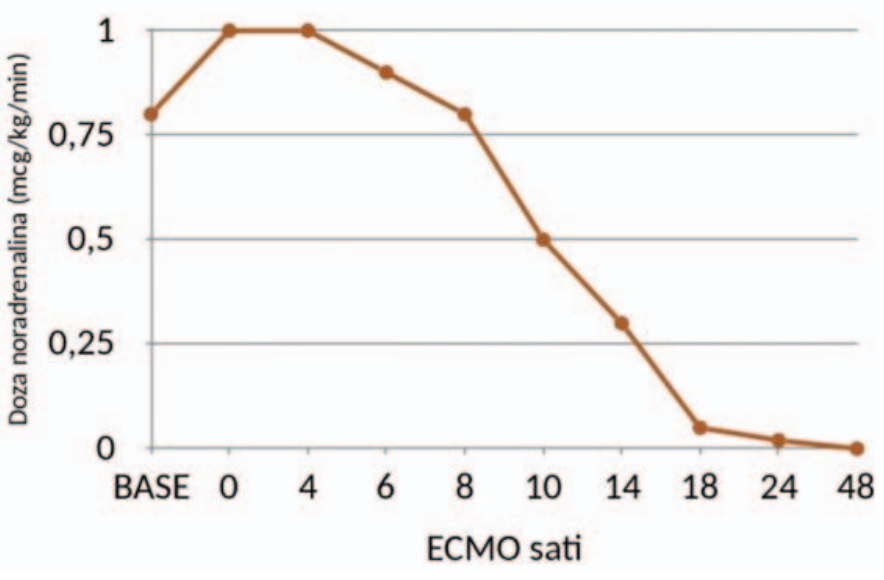

Slika 1. Doze vazokonstrikotrne potpore noradrenalinom prije i poslije postavljanja na VA-ECMO 
tinuous venovenous hemodiafiltration, CVVHDF) putem dijaliznog katetera (Raulerson Duo-Flow IJ, $11,5 \mathrm{Fr} \times 20 \mathrm{~cm}$, MPS Medical Product Service $\mathrm{GmbH}$, Braunfels, Njemačka) postavljenog u lijevu jugularnu venu (Monitor Prismaflex, Baxter Healthcare Corporation, Deerfield, IL, SAD; hemofilter Prismaflex System M100, Baxter Helathcare Corporation, Deerfield, IL, SAD).

Zbog daljnjeg općeg pogoršanja pacijenta u konzultaciji s kardiološkom službom učinila se hitna koronarografija na kojoj se isključio akutni tromboembolijski koronarni incident. Evidentiran je i uredan protok kroz presađeni bubreg. Pacijentovo stanje se dodatno pogoršalo razvojem kardiogenog šoka usprkos eskalaciji medikamentozne terapije te se u konzultaciji s kardiokirurgom pristupilo postavljanju VA-ECMO uređaja ${ }^{5}$. Analizom vaskularnog pristupa, kardiokirurg se odlučio za mješovitu centralno-perifernu kanulaciju VA-ECMO, radi čega je kod pacijenta bilo nužno učiniti resternotomiju s postavljenjem arterijske kanile (Aortic Perfusion Cannula $24 \mathrm{Fr}(8,0 \mathrm{~mm}) \times 20 \mathrm{~cm}$ (8") $3 / 8^{\prime \prime}(9,5 \mathrm{~mm})$ non-vented connector, Edwards LifeSciences, Irvine, CA, SAD) u aortu, a venske kanile (Bio-Medicus Multi-Stage Femoral Venous Cannula with Percutaneous Kit - $25 \mathrm{Fr}(8,3 \mathrm{~mm}) x$ $60 \mathrm{~cm}$, Medtronic PLC, Dublin, Irska) u desnu femoralnu venu. Za mehaničku cirkulacijsku potpo- ru pacijent je bio spojen na Cardiohelp konzolu (Maquet, Hirrlingen, Njemačka) s Maquet oksigenatorom (Bioline set obloženih cijevi s PLS-i (engl. Permanent life support) Oksigenatorom, Bioline, Coimbatore, Indija). Inicijalni protok na uređaju postavljen je na $100 \%$ izračunatog teoretski maksimalnog srčanog minutnog volumena (SMV) pacijenta. Ubrzo po postavljanju, dolazi do dodatne progresije hemodinamskog urušaja radi krvarenja uzrokovanog naglašenom koagulopatijom. Po postavljanju VA-ECMO potpore, hemodinamska stabilnost se održavala uz noradrenalin u dozi od 1 $\mathrm{mg} / \mathrm{kg} / \mathrm{min}$ kontinuirano putem perfuzijske pumpe (Arterenol, Sanofi Aventis, Paris, Francuska i $B$ Braun Medical INC infuzijska pumpa, Melsungen, Njemačka) te se u terapiju također uveo levosimendan u kontinuiranoj primjeni u dozi od 0.1 $\mathrm{mg} / \mathrm{kg} / \mathrm{min}$ (Simdax, Orion Pharma, Ljubljana, Slovenija i B Braun Medical INC infuzijska pumpa, Melsungen, Njemačka) (slika 1). U pacijenta se primijenila opsežna transfuzija krvnih pripravaka, ukupno $2330 \mathrm{ml}$ deleukocitiranih eritrocita, 1920 $\mathrm{ml}$ svježe smrznute plazme i 2 jedinice trombocita. Koagulacijski parametri su se dodatno regulirali primjenom koncentrata faktora zgrušavanja - primijenjeno je 2000 i.j koncentrata protrombinskog kompleksa (Octaplex, Octapharma, Lachen, Švicarska), 2 g fibrinogena (Haemocom-

Tablica 1. Laboratorijski parametri pacijenta - prije i prvih 48 sati poslije postavljanja na VA-ECMO

\begin{tabular}{|c|c|c|c|c|c|c|c|c|c|c|c|}
\hline \multicolumn{2}{|r|}{ ECMO sati } & Prive postavilianso & 0 & 4 & 6 & 8 & 10 & 14 & 18 & 24 & 48 \\
\hline \multirow{3}{*}{$\begin{array}{c}\text { Vitalni } \\
\text { parametri }\end{array}$} & \multirow{3}{*}{$\begin{array}{l}\mathrm{MAP}(\mathrm{mm} \mathrm{Hg}) \\
\text { Frekvencija srca/min } \\
\mathrm{SpO}_{2}\end{array}$} & 76 & 77 & 66 & 67 & 69 & 69 & 70 & 74 & 72 & 70 \\
\hline & & 120 & 130 & 130 & 120 & 105 & 110 & 100 & 95 & 80 & 65 \\
\hline & & $89 \%$ & $100 \%$ & $99 \%$ & $99 \%$ & $99 \%$ & $99 \%$ & $99 \%$ & $98 \%$ & $99 \%$ & $99 \%$ \\
\hline \multirow{3}{*}{ Respirator } & \multirow{3}{*}{$\begin{array}{l}\text { Volumen udaha } \\
\text { PEEP }\end{array}$} & IPPV & IPPV & IPPV & IPPV & IPPV & IPPV & IPPV & IPPV & IPPV & IPPV \\
\hline & & 500 & 380 & 380 & 380 & 380 & 380 & 380 & 380 & 380 & 380 \\
\hline & & 8 & 8 & 8 & 8 & 8 & 8 & 8 & 8 & 8 & 8 \\
\hline \multirow{6}{*}{ ECMO } & \multirow{6}{*}{$\begin{array}{l}\text { Sweep (L/min) } \\
\mathrm{FiO}_{2} \\
\text { Protok pumpe(L/min) } \\
\text { Broj okretaja pumpe/min } \\
\text { Heparin (IU/24h) } \\
\text { ACT (s) }\end{array}$} & & 2,2 & 2,2 & 2 & 4 & 5 & 5 & 3,4 & 3,8 & 3 \\
\hline & & & 0,9 & 0,85 & 0,85 & 0,9 & 0,9 & 0,95 & 0,7 & 0,75 & 0,65 \\
\hline & & & 4,5 & 4,5 & 4,5 & 4,45 & 4,5 & 4,7 & 4,6 & 4,5 & 4,3 \\
\hline & & & 3645 & 3645 & 3595 & 3611 & 3600 & 3685 & 3685 & 3685 & 3700 \\
\hline & & & I & 1 & I & 1 & I & 1 & 10000 & 7500 & 8000 \\
\hline & & & 347 & 196 & 130 & 124 & 122 & 125 & 112 & 124 & 124 \\
\hline \multirow{6}{*}{$\begin{array}{l}\text { Laboratorij i } \\
\quad \text { ABS }\end{array}$} & \multirow{6}{*}{$\begin{array}{l}\mathrm{pH} \\
\mathrm{PaO}_{2}(\mathrm{kPa}) \\
\mathrm{PaCO}_{2}(\mathrm{kPa}) \\
\text { Laktat }(\mathrm{mmol} / \mathrm{L}) \\
\mathrm{Hb}(\mathrm{g} / \mathrm{L}) \\
\mathrm{Hct}(\mathrm{c})\end{array}$} & 7,31 & 7,28 & 7,27 & 7,32 & 7,3 & 7,39 & 7,46 & 7,48 & 7,48 & 7,46 \\
\hline & & 7,45 & 13,5 & 11,7 & 15,52 & 10,5 & 12,5 & 13,5 & 23,4 & 20,8 & 19,6 \\
\hline & & 5,18 & 5,7 & 5,4 & 5,47 & 6,6 & 5,3 & 4,1 & 4,23 & 4,6 & 5,3 \\
\hline & & 4 & 11,4 & 11,5 & 9,4 & 7,1 & 6,1 & 3,4 & 1,6 & 1,5 & 1,4 \\
\hline & & 107 & 79,8 & 80 & 74,4 & 82,2 & 83 & 90 & 85 & 99 & 87 \\
\hline & & 0,32 & 0,24 & 0,24 & 0,22 & 0,26 & 0,26 & 0,27 & 0,25 & 31 & 0,26 \\
\hline $\begin{array}{c}\text { Vazoaktivna } \\
\text { potpora }\end{array}$ & Noradrenalin (mcg/kg/min) & 0,8 & 1 & 1 & 0,9 & 0,8 & 0,5 & 0,3 & 0,05 & 0,02 & 0 \\
\hline
\end{tabular}

MAP - srednji arterijski tlak, $\mathrm{SpO}_{2}$ - zasićenost krvi kisikom, PEEP - Positive end-expiratory pressure, Sweep - protok plinova kroz membranski oksigenator, $\mathrm{FiO}_{2}$ - frakcija udahnutog kisika, $\mathrm{ACT}$ - activated clotting time, $\mathrm{PaO}_{2}$ - parcijalni tlak kisika u krvi, $\mathrm{PaCO}_{2}$ - parcijalni tlak ugljičnog dioksida $\mathrm{u}$ krvi, $\mathrm{Hb}$ - hemoglobin, Hct - hematokrit, IPPV - intermittent positive pressure ventilation 
plettan, CSL Behring GmbH, Marburg, Njemačka) te je nastavljena i kontinuirana primjena traneksamične kiseline (Azeptil, Medochemie LTD, Limassol, Cipar) u dozi od $15 \mathrm{mg} / \mathrm{kg}$ kroz 8 sati, nakon početnog bolusa od $15 \mathrm{mg} / \mathrm{kg}$ tjelesne mase. $\mathrm{Na}$ primijenjenu terapiju dolazi do normalizacije faktora zgrušavanja i vrijednosti Aktiviranog vremena zgrušavanja (engl. activated clotting time (ACT)). Tijekom prva 24 sata od postavljanja VA-ECMO nastavlja se $s$ korekcijom faktora koagulacije i krvne slike, ali dolazi i do značajne hemodinamske stabilizacije pacijenta, što se očituje smanjenjem doze vazoaktivne potpore noradrenalinom i potpunog ukidanja levosimendana te postupne korekcije laboratorijskih parametara, posebice laktacidemije (tablica 1).

Nakon stabilizacije parametara koagulacije, otprilike 14 sati po kanulaciji VA-ECMO, pacijentu se u terapiju uvela kontinuirana infuzija heparina ( $\mathrm{He}$ parin, Panpharma, Luitre, Francuska i B Braun Medical INC infuzijska pumpa, Melsungen, Njemačka). Njegova doza se regulirala mjerenjem ACT svakih 4 - 6 sati prema protokolu ustanove te se održavaju unutar raspona vrijednosti od 120 do 200 sekundi, ovisno o brzini protoka VA-EC -MO. O pacijentu je, sukladno protokolu ustanove, svakodnevno brinuo multidisciplinarni tim medicinskog osoblja. Nadzirala se funkcija transplantata, redovitim ultrazvučnim pregledima, praćenjem diureze i redovitim kontrolama biokemijskih parametara bubrežne funkcije te kvalitativnim i kvantitativnim analizama urina. Imunosupresivna terapija uvedena je drugog dana liječenja te je u daljnjem tijeku primjenjivana prema uputama nefrologa. Serijskim transezofagijskim ehokardiografskim pregledima u pacijenta se pratio postupni oporavak srčane funkcije uz postupno smanjivanje mehaničke cirkulatorne potpore. Pacijent se od potpore radu srca u potpunosti odvojio 9 dana nakon kanulacije.

Postupak odvajanja protekao je uredno, bez komplikacija. Po odvajanju, kod pacijenta se nastavilo s invazivnim hemodinamskim praćenjem, prema kojemu se vodila daljnja volumna i medikamentozna terapija. Tijekom liječenja u JIL-u glukoza u krvi je održavana u granicama raspona (6 - 12 $\mathrm{mmol} / \mathrm{L})$ konvencionalnom inzulinskom terapijom. Pacijentova antimikrobna terapija je regulirana prema mikrobiološkim nalazima.
Po odvajanju od mehaničke cirkulacijske potpore, pacijent se postupno probudio; odvojen je od mehaničke respiracijske potpore i ekstubiran 13 . dana liječenja. $U$ daljnjem tijeku pacijentovo stanje se kompliciralo razvojem upale pluća koja je uzrokovala ponovnu respiracijsku insuficijenciju, koja je zahtijevala ponovnu intubaciju pacijenta. $\mathrm{U}$ terapiju se uveo kolistin (Colistin Alvogen, XeIlia Pharmaceuticals APS, Copenhagen, Danska) $3 \times 1000000$ internacionalnih jedinica (IU). Kako bi se omogućila bolja toaleta dišnih puteva i lakše

Kod pacijenata koji u nekardioloških zahvata dožive perioperacijski akutni infarkt miokarda (AIM) unutarbolnička smrtnost penje se i do $25 \%$. Kardiogeni šok ostaje i dalje velik izazov u modernoj medicini, s obzirom na to da uza svu terapiju smrtnost i dalje dolazi i do $50 \%$. Upravo je razvoj tehnologije VA-ECMO uređaja omogućio da on postane jedan od glavnih modaliteta liječenja kardiogenog šoka.

odvajanje od mehaničke respiracijske potpore u pacijenta je učinjena perkutana dilatacijska traheotomija (PDT) 22. dana liječenja. Po učinjenoj PDT konačno je odvojen od mehaničke potpore respiraciji 28. dana liječenja.

Po stabilizaciji općeg stanja, pacijenta se dogovorno premjestilo na Zavod s nefrologiju s dijalizom radi nastavka njege i liječenja nakon 35 dana intenzivnog liječenja. Iz bolnice je otpušten nakon ukupno 84 dana bolničkog liječenja s potpuno funkcionalnim bubrežnim presatkom.

\section{RASPRAVA}

U svijetu se na godišnjoj razini učini oko 312 milijuna operacija ${ }^{6}$. Kardiovaskularne komplikacije jedan su od vodećih uzroka mortaliteta i morbiditeta kod kirurških pacijenata. Po nekim istraživanjima preko 10 milijuna pacijenata doživi neko kardiovaskularno događanje u nekardijalnim zahvatima ${ }^{7}$. Perioperacijski infarkt miokarda zabilježen je u 729 pacijenata na 100.000 operacija u 2013. godini. Pacijenti koji su bili operirani radi transplantacije solidnih organa činili su drugu najizloženiju skupinu pacijenata s incidencijom od 1,6 $\%^{8}$. Kod pacijenata koji u nekardioloških zahvata dožive perioperacijski akutni infarkt mio- 
karda (AIM) unutarbolnička smrtnost penje se i do $25 \%$. Problem kod kardiovaskularnih perioperativnih događanja je i što velik broj pacijenata nema ishemijskih simptoma i što ih se, po nekim istraživanjima, i do $50 \%$ ne dijagnosticira ${ }^{9,10}$. Akutni infarkt miokarda (AIM) je i dalje vodeći uzrok kardiogenog šoka, po recentnoj literaturi i do u 80 \% slučajeva, a kardiogeni šok se pojavljuje u do 13 \% slučajeva AIM-a i ostaje vodeći uzrok smrtnosti kod pacijenata koji dožive AIM ${ }^{11-14}$.

$U$ prikazanog pacijenta hemodinamska nestabilnost koja se javila u operacijskoj dvorani započela je lanac nepovoljnih događaja koji su konačno kulminirali razvojem akutnog infarkta miokarda (AIM) s kardiogenim šokom. Upravo se u liječenju kardiogenog šoka polažu sve veće nade $u$ mehaničku cirkulatornu potporu koja, u kombinaciji s medikamentoznom potporom, polako postaje standard u liječenju. Mehanička potpora služi kao svojevrsna „zamjena“ srcu i plućima u stanjima kada oni sami nisu sposobni adekvatno obavljati svoju funkciju, a koristi se kao most do oporavka srčane funkcije, palijative, trajne mehaničke potpore srcu ili do transplantacije srca ako je ona potrebna ${ }^{16}$. Upravo je razvoj tehnologije VA-ECMO uređaja omogućio da on postane jedan od glavnih modaliteta liječenja kardiogenog šoka ${ }^{17}$. U prikazanog pacijenta odluka o započinjanju izvantjelesne cirkulacijske potpore donesena je nakon 24 sata liječenja, kada se pokazalo da je stanje šoka refraktorno na primijenjenu medikamentoznu terapiju i pokušaje stabilizacije. VA-ECMO u našem je slučaju pokrenuta, primarno kao metoda spašavanja života pacijenata, uz nadu da će osiguravanje hemodinamske stabilnosti i adekvatne oksigenacije perifernih tkiva stvoriti uvjete i za preživljavanje presatka. Pacijent je odlično reagirao na primjenu izvantjelesne cirkulacije te je već tijekom prvih osam sati primjene VA-ECMO zabilježen značajan pad laktacidemije i značajno smanjenje doze vazokonstriktorne potpore. Isto tako, zahvaljujući primjeni ECMO potpore, uspješno se potpuno ukinula primjena inodilatacijskih lijekova. Pregledom literature, mehanička cirkulacijska potpora uglavnom se koristi kao most prema zajedničkoj transplantaciji srca i bubrega kod pacijenata, te se istraživanja uglavnom te- melje na njezinu utjecaju na poslijeoperacijsku uspješnost transplantacije i utjecaju na smrtnost pacijenata. Mehanička cirkulacijska potpora još jednom se pokazala kao dobar izbor terapije u kardiogenom šoku te je spriječila potencijalno fatalan ishod. Poboljšanjem hemodinamike pacijenta omogućili su se i povoljni uvjeti za dobro funkcioniranje presatka. Pacijent se redovito kontrolira kod nadležnog nefrologa te je u trenutku pisanja ovog prikaza njegov presadak uredne funkcije.

\section{ZAKLJUČCI}

Svake godine u svijetu se obavlja sve veći broj operativnih zahvata i s time raste i broj kardiovaskularnih događanja. Lanac nepovoljnih događaja u opisanom tijeku liječenja, koji je započeo tijekom zahvata, razvojem hemodinamske nestabilnosti, napredovao je do razvoja akutnog infarkta miokarda koji se komplicirao s razvojem kardiogenog šoka. Ako se kardiogeni šok ne liječi zadovoljavajuće medikamentoznom terapijom, nužno je razmišljati o što ranijem uvođenju mehaničke cirkulacijske potpore. Upravo njeno rano uvođenje omogućuje pravodobnu hemodinamsku stabilizaciju pacijenta s rasterećenjem funkcije srce i pluća. Kao što se sve više u literaturi potvrđuje, mehanička cirkulacijska potpora poboljšava preživljavanje pacijenata, a u ovom slučaju pokazala se i kao dobar izbor liječenja u očuvanju funkcije transplantiranog presatka. Tehnologija mehaničke cirkulatorne potpore svakodnevno napreduje te omogućuje da se upotrebljava u sve većeg broja pacijenata. Ostaje nam zaključiti da su potrebna daljnja istraživanja upotrebe mehaničke cirkulatorne potpore u ovoj skupini pacijenata.

Izjava o sukobu interesa: Autori izjavljuju da ne postoji sukob interesa.

\section{LITERATURA}

1. Levey AS, Coresh J, Balk E, Kausz AT, Levin A, Steffes MW et al. National Kidney Foundation practice guidelines for chronic kidney disease: evaluation, classification and stratification. Ann Intern Med 2003;139:137-47.

2. Levey A, Coresh J. Chronic kidney disease. Lancet 2012; 397:165-80.

3. Kasiske BL, Maclean JR, Snyder JJ. Acute myocardial infarction and kidney transplantation. J Am Soc Nephrol 2006;17:900-7. 
4. www.asahq.org [Internet]. Schaumburg (IL). American society of anesthesiologists. c2019 [cited 2019 Dec 14]. Available from: https://www.asahq.org/standards-andguidelines/asa-physical-status-classification-system.

5. Nieminen MS, Fruhwald S, Heunks LM, Suominen PK, Gordon AC, Kivikko $\mathrm{M}$ et al. Levosimendan: current data, clinical use and future development. Heart Lung Vessel 2013;5:227-45.

6. Weiser TG, Haynes AB, Molina G, Lipsitz SR, Esquivel $\mathrm{MM}$, Uribe-Leitz T et al. Estimate of the global volume of surgery in 2012: an assessment supporting improved health outcomes. Lancet 2015;385 Suppl 2:S11.

7. Devereaux PJ, Goldman L, Cook DJ, Gilbert K, Leslie K, Guyatt GH. Perioperative cardiac events in patients undergoing noncardiac surgery: a review of the magnitude of the problem, the pathophysiology of the events and methods to estimate and communicate risk. CMAJ 2005;173:627-34.

8. Smilowitz NR, Gupta N, Guo Y, Berger JS, Bangalore S. Perioperative acute myocardial infarction associated with non-cardiac surgery. Eur Heart J 2017;38:2409-17.

9. Devereaux PJ, Yang H, Yusuf S, Guyatt G, Leslie K, Villar JC et al. Effects of extended-release metoprolol succinate in patients undergoing non-cardiac surgery (POISE trial): a randomised controlled trial. Lancet 2008;371(9627):183947.

10. Devereaux PJ, Goldman L, Yusuf S, Gilbert K, Leslie K, Guyatt GH. Surveillance and prevention of major perioperative ischemic cardiac events in patients undergoing noncardiac surgery: a review. CMAJ 2005;173:779-88.
11. Aissaoui N, Puymirat E, Tabone X, Charbonnier B, Schiele $\mathrm{F}$, Lefevre $\mathrm{T}$ et al. Improved outcome of cardiogenic shock at the acute stage of myocardial infarction: a report from the USIK 1995, USIC 2000, and FAST-MI French Nationwide Registries. Eur Heart J 2012;33:2535-43.

12. Jeger RV, Radovanovic $D$, Hunziker PR, Pfisterer ME, Stauffer JC, Erne $P$ et al. Ten-year incidence and treatment of cardiogenic shock. Ann Intern Med 2008;149: 618-26.

13. Backhaus T, Fach A, Schmucker J, Fiehn E, Garstka D, Stehmeier J et al. Management and predictors of outcome in unselected patients with cardiogenic shock complicating acute ST-segment elevation myocardial infarction: results from the Bremen STEMI Registry. Clin Res Cardiol 2018;107:371-9.

14. Rathod KS, Koganti S, Iqbal MB, Jain AK, Kalra SS, Astroulakis $\mathrm{Z}$ et al. Contemporary trends in cardiogenic shock: incidence, intra-aortic balloon pump utilisation and outcomes from the London Heart Attack Group. Eur Heart J Acute Cardiovasc Care 2018;7:16-27.

15. Mandawat A, Rao SV. Percutaneous mechanical circulatory support devices in cardiogenic shock. Circ Cardiovasc Interv 2017; e004337:10.

16. Hajjar LA, Teboul JL. Mechanical Circulatory Support Devices for Cardiogenic Shock: State of the Art. Crit Care 2019;23:76.

17. Kleeber ME, Haddad EV, Choi CW, McGrane S, Zalawadiya $\mathrm{S}$, Schlendorf $\mathrm{KH}$ et al. Venoarterial extracorporeal membrane oxygenation in cardiogenic shock. JACC Heart Fail 2018;6:503-16. 